\title{
Near-real time cloud retrievals from operational and research meteorological satellites
}

\author{
Patrick Minnis*a ${ }^{*}$, Louis Nguyen ${ }^{\mathrm{a}}$, Rabindra Palikonda ${ }^{\mathrm{b}}$, Patrick W. Heck ${ }^{\mathrm{c}}$, Douglas A. Spangenberg ${ }^{\mathrm{b}}$, David R. \\ Doelling ${ }^{\mathrm{a}}$, J. Kirk Ayers ${ }^{\mathrm{b}}$, William L. Smith, Jr. ${ }^{\mathrm{a}}$, Mandana M. Khaiyer ${ }^{\mathrm{b}}$, Qing Z. Trepte ${ }^{\mathrm{b}}$, Lance A. Avey ${ }^{\mathrm{b}}$, Fu-Lung \\ Chang ${ }^{\mathrm{d}}$, Chris R. Yost ${ }^{\mathrm{b}}$, Thad L. Chee ${ }^{\mathrm{b}}$, Szedung Sun-Mack ${ }^{\mathrm{b}}$ \\ ${ }^{a}$ NASA Langley Research Center, Hampton, VA 23681 USA

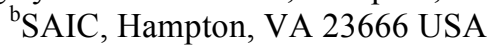 \\ ${ }^{\mathrm{c}}$ CIMSS, Madison, WI 53706 USA \\ ${ }^{\mathrm{d}}$ National Institute of Aerospace, Hampton, VA 23666 USA
}

\begin{abstract}
A set of cloud retrieval algorithms developed for CERES and applied to MODIS data have been adapted to analyze other satellite imager data in near-real time. The cloud products, including single-layer cloud amount, top and base height, optical depth, phase, effective particle size, and liquid and ice water paths, are being retrieved from GOES10/11/12, MTSAT-1R, FY-2C, and Meteosat imager data as well as from MODIS. A comprehensive system to normalize the calibrations to MODIS has been implemented to maximize consistency in the products across platforms. Estimates of surface and top-of-atmosphere broadband radiative fluxes are also provided. Multilayered cloud properties are retrieved from GOES-12, Meteosat, and MODIS data. Native pixel resolution analyses are performed over selected domains, while reduced sampling is used for full-disk retrievals. Tools have been developed for matching the pixellevel results with instrumented surface sites and active sensor satellites. The calibrations, methods, examples of the products, and comparisons with the ICESat GLAS lidar are discussed. These products are currently being used for aircraft icing diagnoses, numerical weather modeling assimilation, and atmospheric radiation research and have potential for use in many other applications.
\end{abstract}

Keywords: Clouds, MODIS, geostationary, real time, nowcasting, icing, GOES, Meteosat, FY-2C, MTSAT

\section{INTRODUCTION}

With the availability of well-calibrated polar-orbiting imagers such as the Moderate Resolution Imaging Spectroradiometer (MODIS) ${ }^{1}$ on the Terra and Aqua satellites, faster computers, new multispectral imagers on geostationary satellites (GEOsats), and spaceborne lidars and radars on the Cloud-Aerosol Lidar and Infrared Pathfinder Satellite Observations (CALIPSO) ${ }^{2}$, the Ice, Cloud, and Elevation Satellite (ICESat) ${ }^{3}$, and CloudSat ${ }^{4}$, it is now possible to provide, in near-real time, more accurate cloud and radiation products than ever before. There remain, however, many obstacles to effectively utilize those resources to actually produce cloud and radiation properties for use in nowcasting and numerical weather prediction models over the globe. This paper describes a prototype system developed to analyze global geostationary satellite data at many scales for both research and potential operational applications.

\section{DATA}

\subsection{Satellite data}

Imager radiance data from the Geostationary Operational Environmental Satellites (GOES-E and GOES-W), and the European Meteosat Second Generation, the Chinese Fengyun (FY-2C), and the Japanese Multi-Functional Transport Satellite (MTSAT-1R) satellites functionally provide coverage at all latitudes equatorward of $\sim 60^{\circ}$ latitude. Terra and Aqua or the operational polar-orbiting meteorological satellites can provide coverage at higher latitudes. While all of these satellites have imagers with five or more channels, not all are useful for cloud monitoring. As seen in Table 1, all of the referenced satellites have three similar spectral channels that are useful for cloud detection and retrievals, and six of the imagers hold a fourth relevant channel (split-window, $12.0 \mu \mathrm{m}$ ) in common. Four of the imagers have a $\mathrm{CO}_{2}$ slicing channel that is also used for cloud retrievals. The nominal resolutions common to all channels on a given imager

*Patrick.Minnis-1@nasa.gov; phone 1757 864-5671; fax 1757 864-7996; www-pm.larc.nasa.gov 
Table 1. Satellite imager channels used in common for cloud detection and retrievals.

\begin{tabular}{|c|c|c|c|c|c|c|c|}
\hline \multirow{2}{*}{ Satellite } & \multirow{2}{*}{$\begin{array}{c}\text { Sub-satellite } \\
\text { Longitude or } \\
\text { Equator Crossing } \\
\text { Time } \\
\end{array}$} & \multirow{2}{*}{$\begin{array}{l}\text { Common } \\
\text { (visible) } \\
\text { resolution, } \\
\mathrm{km}\end{array}$} & \multicolumn{5}{|c|}{ Central or radiance equivalent channel wavelength, $\mu \mathrm{m}$} \\
\hline & & & $\begin{array}{l}\text { Visible } \\
\text { (VIS) }\end{array}$ & $\begin{array}{c}\text { Shortwave-IR } \\
\text { (SIR) }\end{array}$ & $\begin{array}{l}\text { Infrared } \\
\text { (IR) }\end{array}$ & $\begin{array}{l}\text { Split-window } \\
\text { (SW) }\end{array}$ & $\mathrm{CO}_{2}$ \\
\hline GOES-11 & $135^{\circ} \mathrm{W}$ & $4(1)$ & 0.651 & 3.91 & 10.7 & 12.0 & $\mathrm{~N} / \mathrm{A}$ \\
\hline GOES-12 & $75^{\circ} \mathrm{W}$ & $4(1)$ & 0.651 & 3.92 & 10.7 & $\mathrm{~N} / \mathrm{A}$ & 13.3 \\
\hline Meteosat & $0^{\circ}$ & $3(1)$ & 0.640 & 3.92 & 10.8 & 12.0 & 13.4 \\
\hline FY-2C & $105^{\circ} \mathrm{E}$ & $5(1.25)$ & 0.724 & 3.79 & 10.8 & 12.0 & $\mathrm{~N} / \mathrm{A}$ \\
\hline MTSAT-1R & $140^{\circ} \mathrm{E}$ & $5(1.25)$ & 0.724 & 3.79 & 10.8 & 12.0 & N/A \\
\hline Aqua & $1330 \mathrm{LT}$ & $1(0.25)$ & 0.646 & 3.79 & 10.8 & 12.0 & 13.3 \\
\hline Terra & $1030 \mathrm{LT}$ & $1(0.25)$ & 0.646 & 3.78 & 10.8 & 12.0 & 13.3 \\
\hline
\end{tabular}

vary from 1 to $5 \mathrm{~km}$. Higher resolution visible (VIS) channels are available on all of the imagers. Full-disk data from the GEOSats are available from, at least, hourly (Meteosat, MTSAT-R, FY-2C) to 3-hourly (GOES). The Meteosat fulldisk data are available at higher temporal resolution, while nearly full-disk images can be constructed hourly from the GOES subsection images. Higher temporal resolution images of subsections are available from all of the GEOSats. The polar-orbiting satellites sample a given area 6-8 times per day in the polar latitudes. In this paper, the MODIS data are only used in reference to calibration; their use in near-real time global cloud analyses is considered in future studies.

\subsection{Satellite calibrations}

Each GEOSat imager channel is calibrated against the corresponding Terra or Aqua MODIS channel using a variety of techniques $^{5-7}$, unless the channel spectral differences are too large (e.g., 3.79 vs. $3.92 \mu \mathrm{m}$ ) or sampling is too limited. They are also cross-calibrated against each other ${ }^{8}$. If the differences are small, the nominal calibrations are used. The satellite calibrations are performed each month and the coefficients are updated online for the VIS channels. The Terra and Aqua VIS channels were found to be very stable and their measured reflectances differ by only $1 \%$ for a given scene $^{9}$. Figure 1 shows the Meteosat-9 and MTSAT-1R VIS channel calibrations against the Terra and Aqua MODIS VIS channels, respectively, for June 2007. The GEOSat data are given in brightness or squared brightness counts (CNT). The Meteosat-9 data (Fig. 1a) are tightly correlated with the Terra radiances, especially at the low end. The slopes of these linear regression fits vary little from month to month and exhibit a slight upward trend (Fig. 1b), suggesting some degradation in the Meteosat-9 VIS response. Scatter between the MTSAT squared counts and Aqua radiances is much greater, even at the low end. Although, the MTSAT-1R data are also available in 10-bit counts that are supposed to be linear in radiance, the scatterplots and fits are very similar. The spread of the MTSAT counts at the low end is a consistent, known problem that still seeks a solution. The FY-2C VIS channel yields similar results, but with more scatter. The correlations between the MODIS and GOES VIS channels are similar to those in Fig. 1a. Problems in accurately calibrating the MTSAT and FY-2C VIS channels introduce uncertainty in the retrievals.
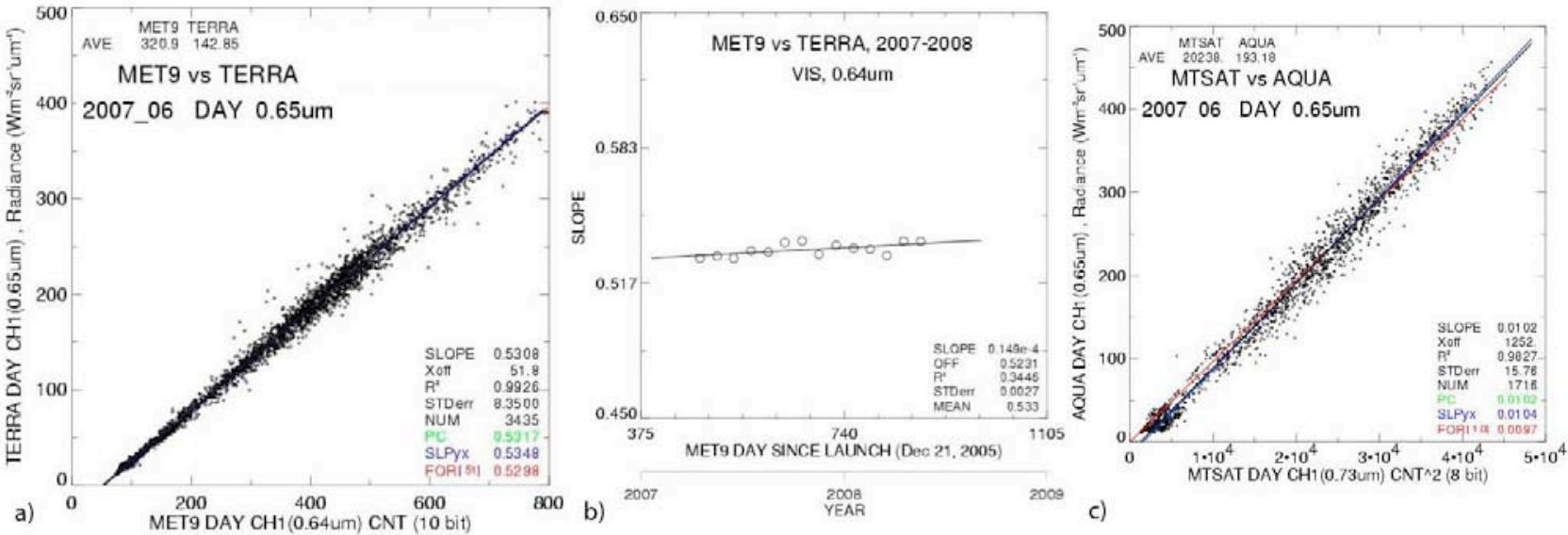

Fig. 1. Correlations and regression fits between (a) Meteosat-9 and Terra MODIS VIS channels and (c) MTSAT-1R and Aqua MODIS VIS channels, June 2007. Standard linear fit in black, principal component fit in green, reversed axis linear fit in blue, and force fit to zero or known space count in red. (b) slopes of linear regression fits between Meteosat-9 and Terra MODIS VIS channels. 

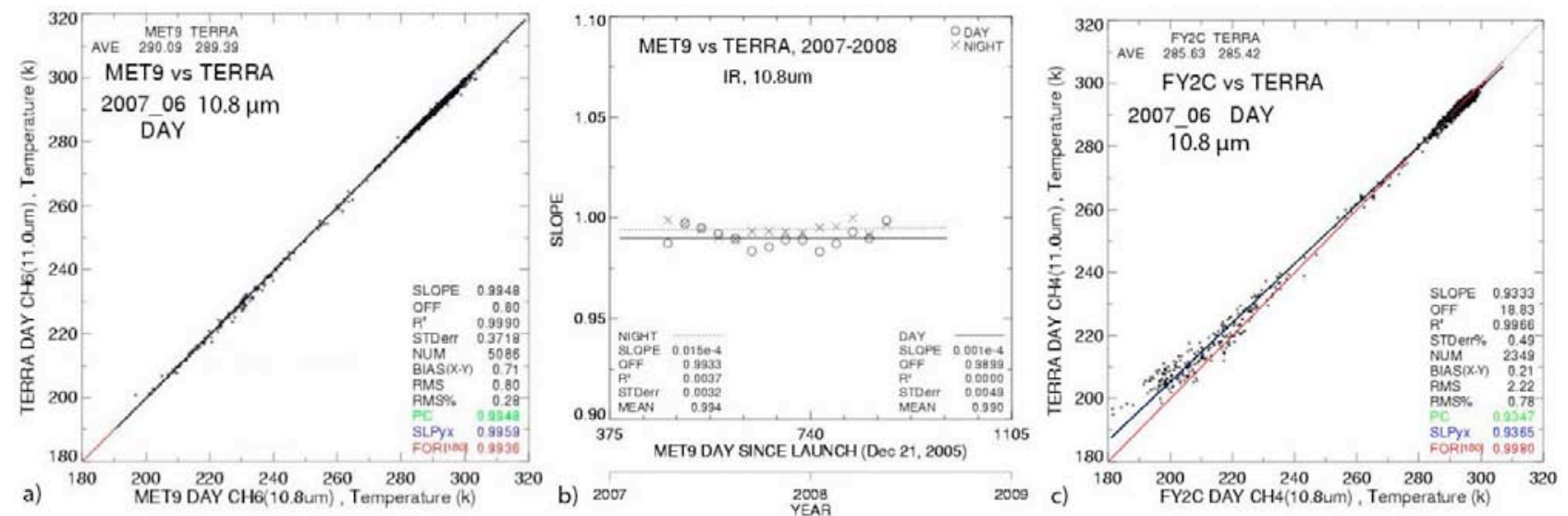

Fig. 2. Same as Fig. 1, except for IR channels and (c) Terra versus FY-2C.

The IR channel calibrations show similar differences between the reference and GEOSats. The Meteosat-9 IR brightness temperatures are highly correlated with and show little scatter relative to the Terra values (Fig. 2a) but are, on average, $0.8 \mathrm{~K}$ greater than the Terra values during the day. At night (not shown), the difference is $0.6 \mathrm{~K}$. This small day-night discrepancy is reflected in the small differences between the monthly slopes (Fig. 2b). The fits between the Terra and other GEOSat IR channels are similarly correlated, except for FY-2C. Both GOES IR channels have a $0.3 \mathrm{~K}$ day-night discrepancy relative to the Terra IR channel, but the average bias is close to zero. No day-night difference is evident in the MTSAT-Terra bias, which is less than $0.2 \mathrm{~K}$. The relationships between the FY-2C and Terra IR temperatures vary from month to month. As seen Fig. 2 c, the greatest discrepancies occur at lower temperatures. In this case, the Terra values are greater than their FY-2C counterparts for temperatures, $T<250 \mathrm{~K}$. During other months, there is agreement at the low end, while, at other times, the low Terra temperatures are less than the FY-2C values. While part of this variation may be attributable to navigation errors in the FY-2C data, it is mirrored in crosscalibrations with MTSAT and Meteosat (not shown) indicating some significant stability uncertainties in the FY-2C IR data. The comparisons between the Terra split-window channels and those on each GEOSat are very much like those for the IR channels.

The GEOSat SIR channels are also relatively well behaved, except for the FY-2C. The correlations among the GOES11, GOES-12, and Meteosat-9 are all very tight (Fig. 3b, c), although the GOES-12 measures higher temperatures than Meteosat-9. The MTSAT SIR temperatures are highly correlated with their Aqua counterparts (Fig. 3a) and the mean day and night Aqua-MTSAT SIR temperature differences are 0.7 and $0.4 \mathrm{~K}$, respectively. Day-night differences in the GOES-11/12 and GOES-12/Meteosat-9 biases are around $\pm 0.1 \mathrm{~K}$. The FY-2C SIR channel is generally well behaved during the daylight hours, yielding good correlations and month-to-month consistency in the calibration fits against Aqua data, despite significant temperature differences. The average daytime slope and offsets are1.085 and $-24.85 \mathrm{~K}$.
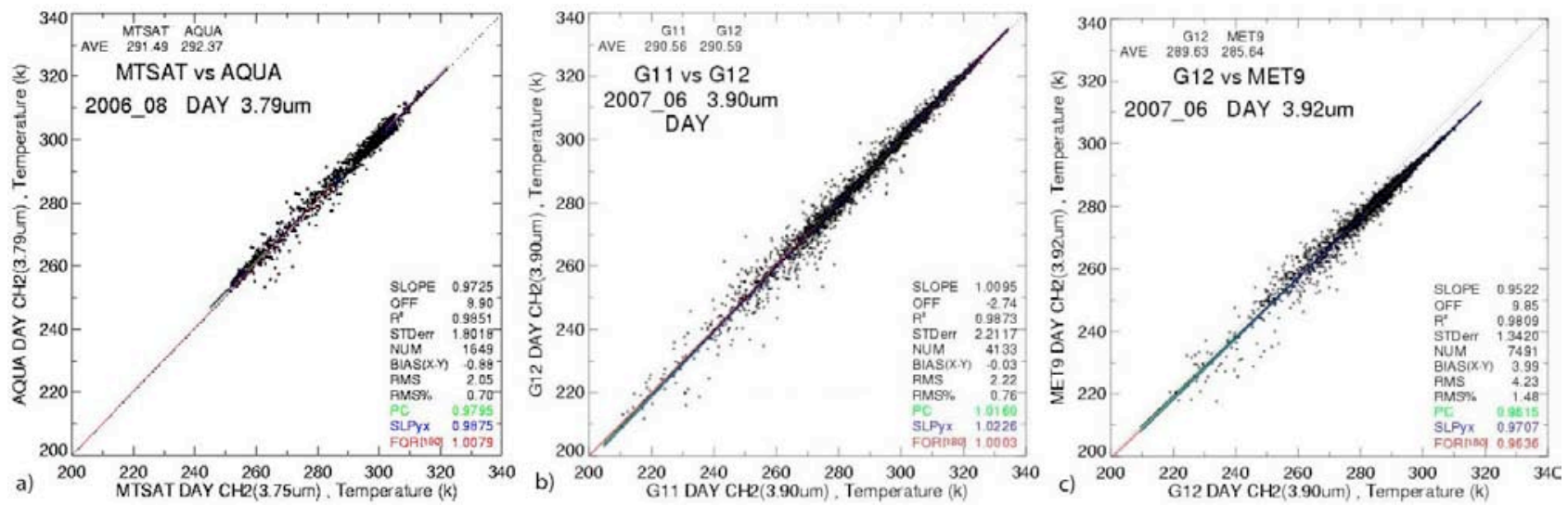

Fig. 3. Correlations and regression fits between daytime SIR data from (a) MTSAT-1R and Aqua MODIS, August 2006 and on (b) GOES-11 and GOES-12, and (c) GOES-12 and Meteosat-9, June 2007. Different fits explained as in Fig. 1. 

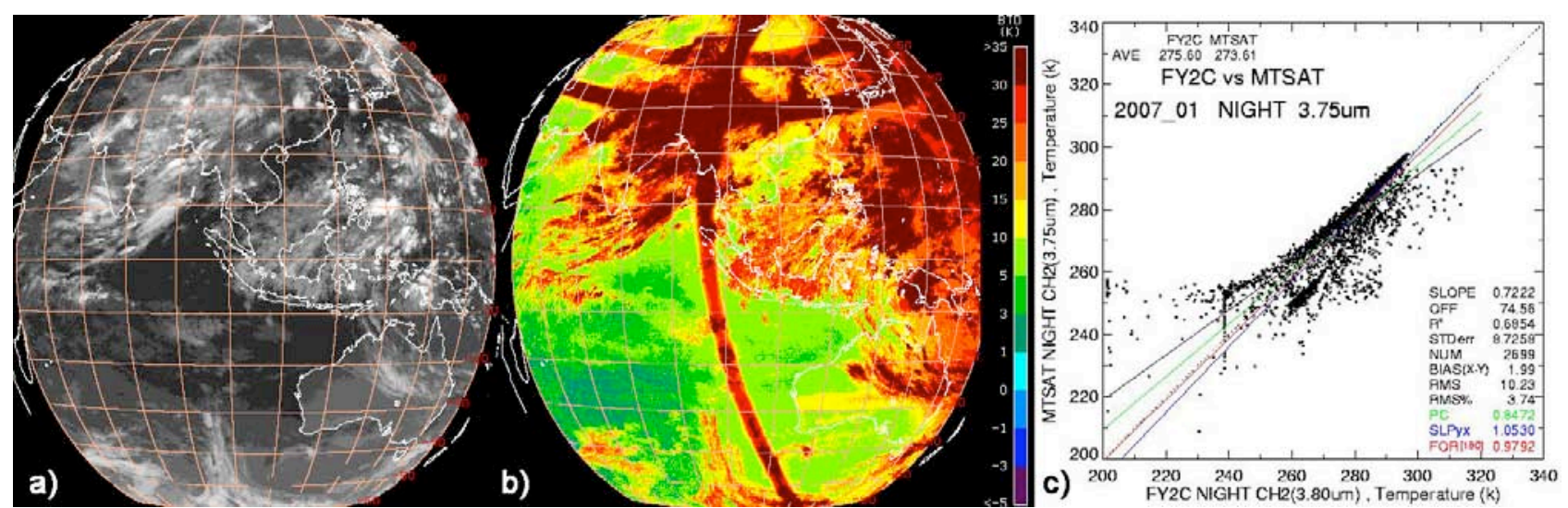

Fig. 4. Nighttime FY-2C images, 1800 UTC, 13 August 2008 (a) IR and (b) SIR-IR temperature difference. (c) Correlations and regression fits between nighttime SIR data from (a) FY-2C and MTSAT-1R. Different fits explained as in Fig. 1.

At night, there are a number of erratic irregularities in the FY-2C SIR channel that include an east-west gradient and strange, varying striping patterns, as well as wholesale shifts in the gain. Figure 4 shows an example of two of the irregularities and the typical impact on intercalibration. The 1800 UTC, 13 August 2008 IR image (Fig. 4a) shows apparently normal behavior, while the corresponding SIR-IR brightness temperature difference (BTD) image (Fig. 4b) reveals a double cross near the middle and a large area in the east with values exceeding $20 \mathrm{~K}$. Other large areas appear to be perfectly normal. This type of behavior is seen nearly every day between 1500 and 1800 UTC rendering those images nearly useless for inclusion in the calibrations and retrievals, but the behavior at other hours is more normal.

Shortwave (SW) and longwave (LW) fluxes at the top of the atmosphere (TOA) are computed from the VIS and IR data, respectively, using narrow-to-broadband conversion functions ${ }^{10}$. The coefficients for those functions have been updated ${ }^{11}$ using narrowband data matched to measured broadband fluxes from the Clouds and the Earth's Radiant Energy System (CERES) project ${ }^{12}$.

\subsection{Auxiliary data}

Surface temperatures and profiles of temperature, humidity, and ozone are interpolated to a given location and time from the 6-hourly, $1.25^{\circ}$ NOAA Global Forecast System (GFS) analyses and forecasts. Clear-sky albedos, surface emissivities, surface types, and snow and ice cover are estimated as for CERES ${ }^{13}$.

\section{METHODOLOGIES}

The pixel-level data are processed in a tile format. Each tile consists of all pixels in a $0.5^{\circ}$ or $1^{\circ}$ region, depending on the domain. Currently, the GEOSat data full-disk images are sampled to achieve a nominal resolution between 8 and 10 $\mathrm{km}$, depending on the satellite. The surface temperatures, clear-sky radiances, surface types, and spectral atmospheric corrections are computed once for each tile and then used to classify each pixel as clear or cloudy ${ }^{13}$. Cloud properties are retrieved for each cloudy pixel using the VIS-IR-SIR-SWC Technique (VISST) during the day and the SIR-IR-SWC Technique (SIST) at night ${ }^{14}$. Daytime is defined as all times when the solar zenith angle (SZA) is less than $82^{\circ}$. At night, the SIST is modified to use the $\mathrm{CO}_{2}$ channel instead of the SWC for GOES-12. In that instance, the $\mathrm{CO}_{2}$ and IR channels are used to assign the cloud height and optical depth, while the IR and SIR channels are used to estimate the particle size. At night, the cloud particle sizes, optical depths, and water paths are only estimated for optically thin clouds (optical depths less than 3 or so). For optically thick clouds, default values are used at night.

Table 2 lists the retrieved pixel-level cloud properties and radiation parameters. The near-infrared (NIR; 1.62 or 2.13 $\mu \mathrm{m})$ reflectance and water vapor $(\mathrm{WV} ; 6.7 \mu \mathrm{m})$ temperatures are included for the satellites having those channels. The scene ID or cloud mask indicates whether the pixel is cloudy, snow-free clear, or snow-covered clear. Aircraft icing potential is derived from the liquid water path, effective temperature, and effective droplet size ${ }^{15}$. The viewing zenith (VZA) and relative azimuth (RAA) angles are included along with the SZA for each pixel. 
Table 2. Output parameters from GEOSat analyses.

\begin{tabular}{|c|c|c|c|}
\hline \multicolumn{4}{|c|}{ Pixel-Level Products - all pixels } \\
\hline VIS reflectance & NIR reflectance & $\mathrm{BTD}(\mathrm{SIR}-\mathrm{IR})$ & WV temperature \\
\hline IR temperature & BTD(IR-SWC) & $\mathrm{BTD}\left(\mathrm{IR}-\mathrm{CO}_{2}\right)$ & scene ID (cloud mask) \\
\hline TOA shortwave albedo & TOA longwave flux & icing potential & SZA, VZA, RAA \\
\hline latitude & longitude & & \\
\hline \multicolumn{4}{|c|}{ Pixel-Level Products - cloudy pixels only } \\
\hline phase & optical depth & droplet/crystal size & liquid/ice water path \\
\hline effective temperature & effective pressure & top pressure & bottom pressure \\
\hline IR emissivity & effective height & top height & bottom height \\
\hline \multicolumn{4}{|c|}{ Gridded Products } \\
\hline total cloud percentage & total cloud property means & total cloud property SDs & mean SZA, VZA, RAA \\
\hline level cloud percentages & level cloud property means & mid cloud property means & high cloud property means \\
\hline VIS reflectance & IR temperature & SIR temperature & clear-sky IR temperature \\
\hline clear-sky VIS reflectance & clear-area skin temperature & mean column RH & TOA shortwave albedo \\
\hline TOA longwave flux & surface SW flux up & surface SW flux down & surface LW flux up \\
\hline surface LW flux down & & & \\
\hline
\end{tabular}

The pixel-level products are also averaged over the tiles to produce gridded properties. The cloud amount and the standard deviations (SD) are also provided for the total cloud properties. Similar averages are computed for the low $(<2$ $\mathrm{km})$, middle $2-6 \mathrm{~km}$ ) and high $(>6 \mathrm{~km}$ ) cloud layers. Several other parameters are also computed for each tile including the surface radiative fluxes ${ }^{11}$, the surface skin temperature, VIS reflectance, and IR temperature for clear areas, and the mean relative humidity $(\mathrm{RH})$ derived from the GFS data for the column above the surface. Currently, not all gridded products are available for all domains.

The results of the analyses and the means for displaying and comparing them are described by Palikonda et al. ${ }^{16}$. These data and the tools can be accessed at http://www-angler.larc.nasa.gov/satimage/products.html.

\section{RESULTS}

Examples of the combined full-disk products are shown in Fig. 5 for 1800 UTC, 13 June 2008. Except for Meteosat-9, the analyses are confined to latitudes equatorward of $60^{\circ}$ latitude. The pseudocolor RGB image (Fig. 5a) shows the terminator while providing some continuity between sunlit and dark portions of the globe. Areas of sunglint are evident, centered around $115^{\circ} \mathrm{W}, 80^{\circ} \mathrm{W}$, and $30^{\circ} \mathrm{W}$ near $15^{\circ} \mathrm{N}$. Except for GOES-11 and 12, the demarcation of the different satellites is easy to see, especially for FY-2C. The odd striping in the FY-2C SIR channel appears in this image also. Cloud-top height (Fig. 5b) also shows some satellite boundary lines, but for the Meteosat-9, the terminator boundary shows up in some areas (e.g., Africa) as a change in cloud height. Overall, the cloud-top heights are relatively consistent from one satellite to the next. The calibration problems for FY-2C seem to mostly affect the heights of the very thin high clouds. The optical depths (OD) in Fig. 5c and effective droplet radii (Re) in Fig. 5d also show the terminator lines because of the limitations of using thermal channels alone. The optical depths in the daylight sector range up to much larger values than over the dark regions. The effective droplet radii in the sunlit areas are very reasonable and show patterns similar to those seen from MODIS retrievals ${ }^{14}$, relatively small values near the coasts and much larger droplets in open marine areas. Currently, the full-disk results are only provided online in separate formats. A combined product such as that shown here will be available in the future when some of the satellite calibration and terminator problems have been resolved satisfactorily.

The derived cloud and radiative properties have been compared against a variety of surface, aircraft, and other satellite datasets to assess their accuracies ${ }^{11,17-19}$. Evaluation of the retrieved cloud properties is continuing as more reference data become available from various satellites and surface sites. The October 2003 cloud layering product from the ICESat Geoscience Laser Altimeter System ${ }^{20}$ (GLAS) were matched with the GOES cloud products over the contiguous USA using two methods: one assigns GLAS footprints to individual GOES pixels and the second assigns the GLAS 


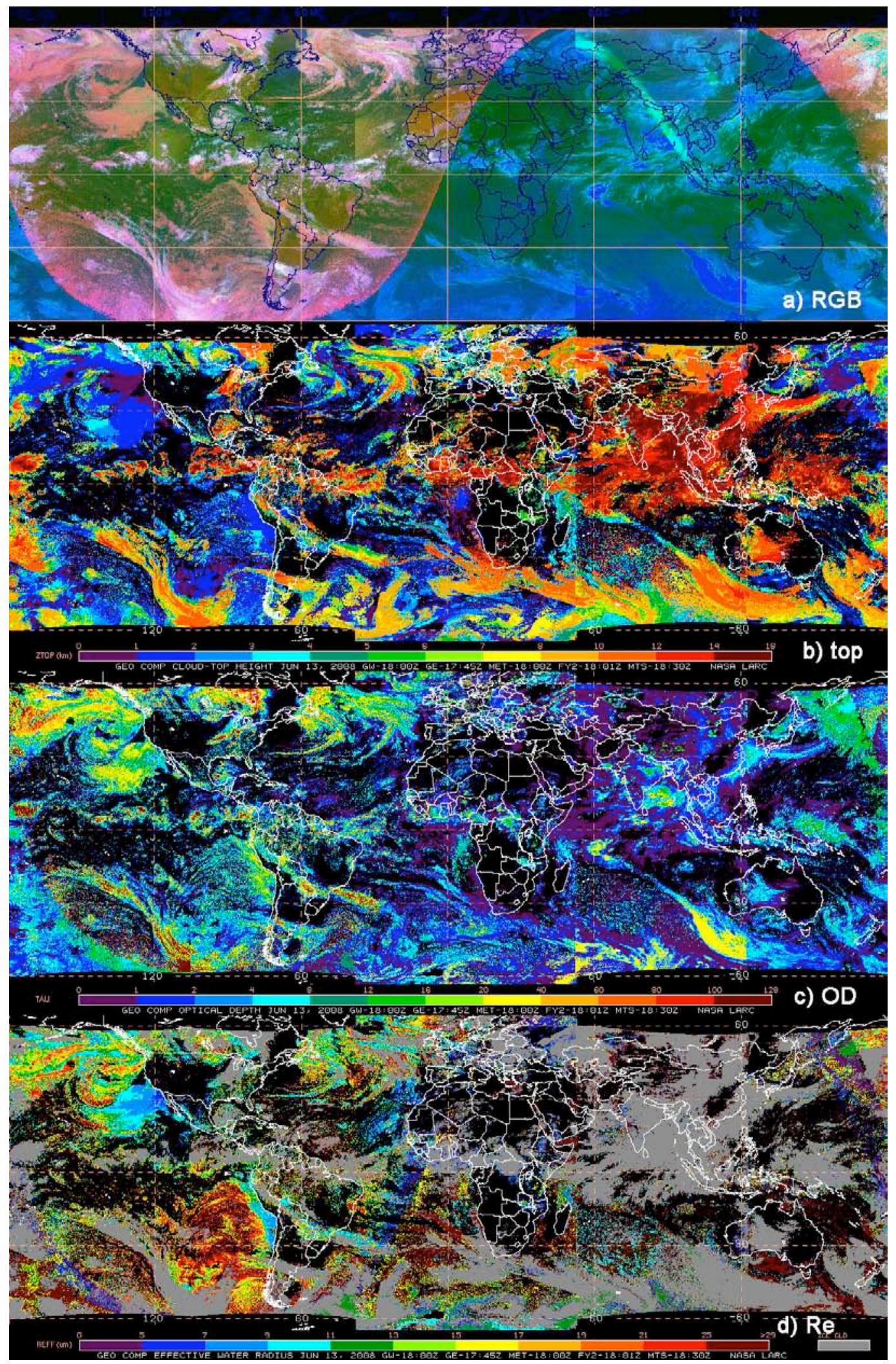

Fig. 5. Combined imagery and cloud properties from GOES-11, GOES-12, Meteosat-9, FY-2C, and MTSAT-1R, 1800 UTC, 13 June 2008. (a) RGB image created using combination of VIS, IR, and SIR data. 

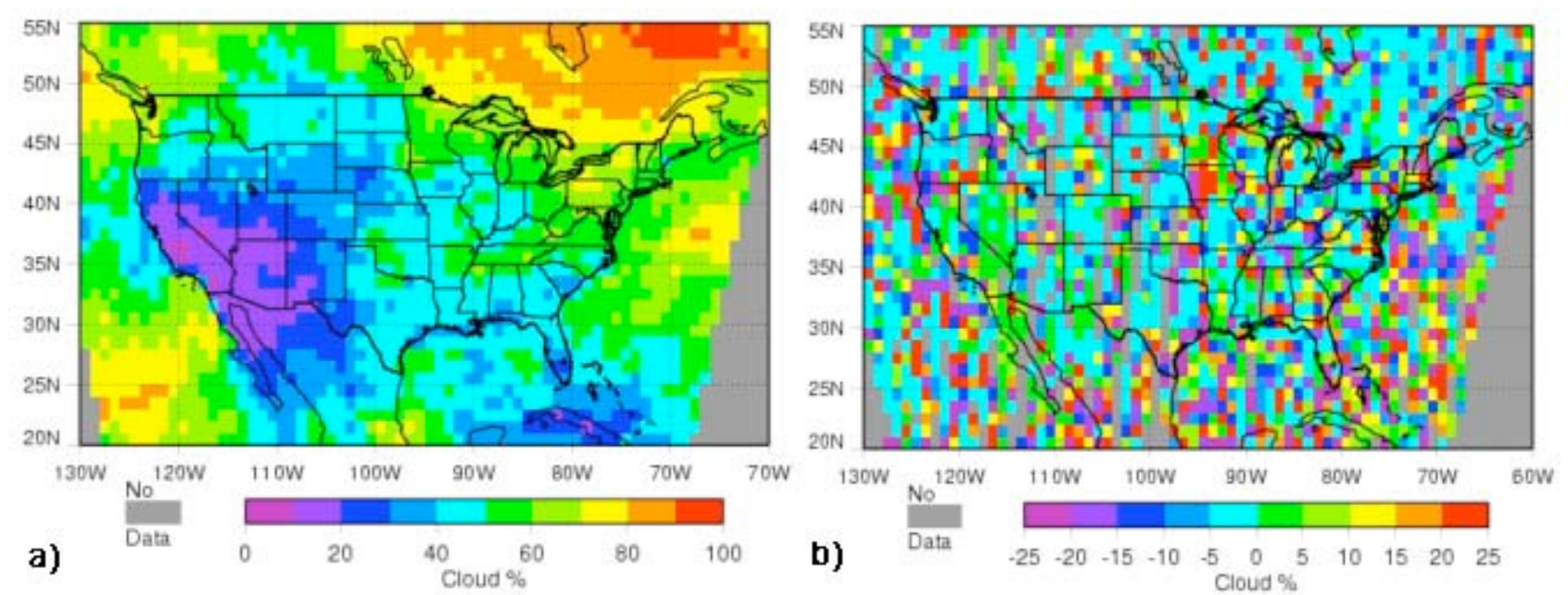

Fig. 6. Daytime cloud amounts and differences over the contiguous USA domain, October 2003. (a) Combined mean $0.5^{\circ}$ GOES10/12 cloud amounts. (b) Differences between ICESat GLAS and matched GOES $0.5^{\circ}$ cloud amounts.

footprints to a given $0.5^{\circ}$ region. Results for the second method are shown in Fig. 6 for daytime cloud fraction. Cloud amount differences of $\pm 5 \%$ predominate over areas with large and small mean cloud amounts. Comparisons of cloud amounts and heights yielded similar results for both approaches. During the daytime, the mean GOES cloud amounts were $52 \%$ for both methods compared to $55 \%$ from GLAS. At night, the GLAS average cloud amount was $64 \%$ because of its increased sensitivity to optically thin clouds, those with optical depths less than $\sim 0.3$. The GOES cloud amounts dropped to $51 \%$. These results are similar other comparisons indicating the passive measurements detect few clouds with $\mathrm{OD}<0.3$.

On average, the GOES cloud-top heights were $4.8 \mathrm{~km}$ during the day compared to $5.2 \mathrm{~km}$ from GLAS. At night, the bias increased from -0.4 to $-1.9 \mathrm{~km}$, primarily because the SIST was not using the $\mathrm{CO}_{2}$ channel for GOES- 12 at that time. Multi-layered clouds tend to cause an underestimate of cloud-top height. If only single-layer clouds are considered, the VISST tends to overestimate cloud-top height while the SIST still underestimates cloud height. A more comprehensive study ${ }^{21}$ over a surface site in Oklahoma showed better agreement in single-layer cloud heights, perhaps because of more sampling and the use of GOES10/11 data instead of GOES-12. Initial comparisons of GLAS heights derived from GOES-12 using a new IR- $\mathrm{CO}_{2}$ multi-layered cloud retrieval method ${ }^{21}$ show significant improvement in the heights.

\section{CONCLUDING REMARKS}

A comprehensive system has been developed for producing nearly global cloud products in near-real time for a variety of applications including numerical weather model assimilation and nowcasting. The results from regional and full-disk analyses are now available online for use by the community. While many improvements can be made to the system, the greatest remaining obstacles to producing a continuously reliable product are consistent calibrations across all platforms and new techniques to address issues around the terminator. Retrievals over snow-covered surfaces are also potentially biased because of the decrease in contrast between the clouds and snow. Availability of 1.6- $\mu \mathrm{m}$ channels on Meteosat and the future GOES-R will help alleviate that problem. Integration of the new IR- $\mathrm{CO}_{2}$ multilayered cloud retrieval method, currently applied to GOES-12 and Meteosat data and applicable to GOES-R, into this system will improve the accuracy of the cloud-top heights. Validation studies using GLAS, CALIPSO, CloudSat and surface site data will continue and the results will be used to update the analysis codes.

\section{ACKNOWLEDGMENTS}

This research was sponsored by the NASA Science Mission Directorate through the Applied Sciences Program and the ICESat Project, the Department of Energy Atmospheric Radiation Measurement Program, and the NOAA GOES-R Program. 


\section{REFERENCES}

[1] Barnes, W. L., T. S. Pagano, and V. V. Salomonson, "Prelaunch characteristics of the Moderate Resolution Imaging Spectroradiometer (MODIS) on EOS-AM1," IEEE Trans. Geosci. Remote Sens. 36, 1088-1100 (1998).

[2] Winker, D. M., W. H. Hunt, and M. J. McGill, "Initial performance assessment of CALIOP," Geophys. Res. Lett. 34, L19803, doi:10.1029/2007GL03135 (2007).

[3] Schutz, B. E., H. J. Zwally, C. A. Shuman, D. Hancock, and J. P. DiMarzio, "Overview of the ICESat Mission," Geophys. Res. Lett. 32, L21S01, doi:10.1029/2005GL024009 (2005).

[4] Stephens, G. L., et al., "The CloudSat Mission and the A-Train: A new dimension of space-based observations of clouds and precipitation,” Bull. Amer. Meteor. Soc. 83, 1771-1790 (2002).

[5] Minnis, P., et al., "Rapid calibration of operational and research meteorological satellite imagers, Part I: Evaluation of research satellite visible channels as references," J. Atmos. Oceanic Technol. 19, 1233-1249 (2002).

[6] Minnis, P., et al., "Rapid calibration of operational and research meteorological satellite imagers, Part II: Comparison of infrared channels," J. Atmos. Oceanic Technol. 19, 1250-1266 (2002).

[7] Nguyen, L., D. R. Doelling, P. Minnis, and J. K. Ayers, "Rapid technique to cross calibrate satellite imager visible channels," Proc. SPIE 5542, 227-235 (2004).

[8] Doelling, D. R., L. Nguyen, and P. Minnis, "On the use of deep convective clouds to calibrate AVHRR data," Proc. SPIE 5542, 281-289 (2004).

[9] Minnis, P., D. R. Doelling, L. Nguyen, W. F. Miller, and V. Chakrapani, "Assessment of the visible channel calibrations of the TRMM VIRS and MODIS on Aqua and Terra," J. Atmos. Oceanic Technol. 25, 385-400 (2008).

[10] Minnis, P. and W. L. Smith, Jr., "Cloud and radiative fields derived from GOES- 8 during SUCCESS and the ARMUAV Spring 1996 Flight Series," Geophys. Res. Lett. 25, 1113-1116 (1998).

[11] Khaiyer, M. M., et al., "Derivation of improved surface and TOA broadband fluxes using CERES-derived narrowband-to-broadband coefficients," Proc. AMS 12th Conf. Atmos. Radiation, Madison, WI, July 10-14, CDROM, P3.5 (2006).

[12] Wielicki, B. A., et al., "Clouds and the Earth's Radiant Energy System (CERES): Algorithm overview," IEEE Trans. Geosci. Remote Sens. 36, 1127-1141, (1998).

[13] Minnis, P., et al., "Cloud detection in non-polar regions for CERES using TRMM VIRS and Terra and Aqua MODIS data," IEEE Trans. Geosci. Remote Sens., in press, (2008).

[14] Minnis, P., et al., "Cloud property retrieval techniques for CERES using TRMM VIRS and Terra and Aqua MODIS data," IEEE Trans. Geosci. Remote Sens., submitted, (2008).

[15] Minnis, P., et al., "Real-time cloud, radiation, and aircraft icing parameters from GOES over the USA," Proc. $13^{\text {th }}$ AMS Conf. Satellite Oceanogr. and Meteorol., Norfolk, VA, Sept. 20-24, CD-ROM, P7.1 (2004).

[16] Palikonda, R., et al., "NASA-Langley web-based operationl real-time cloud retrieval products from geostationary satellites," Proc. SPIE 6408 (2006).

[17] Mace, G. G., T. P. Ackerman, P. Minnis, and D. F. Young, "Cirrus layer microphysical properties derived from surface-based millimeter radar and infrared interferometer data," J. Geophys. Res. 103, 23,207-23,216 (1998).

[18] Dong, X., et al., "Comparison of stratus cloud properties deduced from surface, GOES, and aircraft data during the March 2000 ARM Cloud IOP,” J. Atmos. Sci. 59, 3256-3284 (2002).

[19] Min, Q, P. Minnis, and M. M. Khaiyer, "Comparison of cirrus optical depths from GOES-8 and surface measurements," J. Geophys. Res. 109, D20119, 10.1029/2003JD004390, (2004).

[20] Spinhirne, J. D., S. P. Palm, W. D. Hart, D. L. Hlavka, and E. J. Welton, "Cloud and aerosol measurements from GLAS: Overview and initial results," Geophys. Res. Lett. 32, L22S03, doi: 10.1029/2005GL023507 (2005).

[21] Smith, W. L., P. Minnis, H. Finney, R. Palikonda, and M. M. Khaiyer, "An evaluation of operational GOESderived single-layer cloud top heights with ARSCL over the ARM Southern Great Plains site," Geophys. Res. Lett. 35, L13820, doi:10.1029/2008GL034275 (2008).

[22] Chang, F.-L., P. Minnis, B. Lin, S. Sun-Mack, and M. Khaiyer, "Properties of cirrus overlapping clouds as deduced from the GOES-12 imagery data," Proc. AMS 12th Conf. Atmos. Radiation, CD-ROM, JP2.9 (2006). 